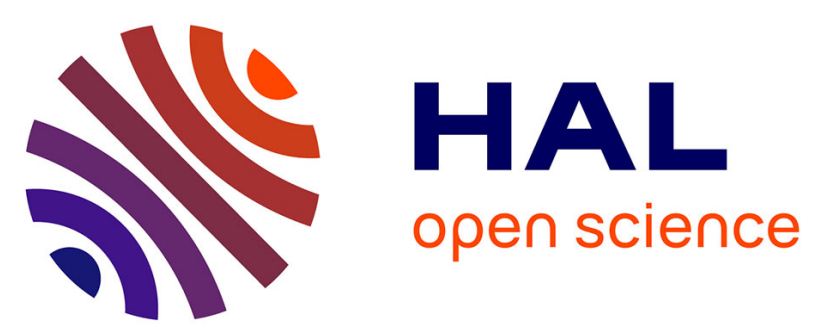

\title{
A musculoskeletal modelling approach of the assessment of the risk of hamstring injuries in professional soccer players: A pilot study
}

Mathieu Ménard, A. Sorel, R Boumpoutou, Hugo A. Kerherve, Richard Kulpa, Benoit Bideau

\section{To cite this version:}

Mathieu Ménard, A. Sorel, R Boumpoutou, Hugo A. Kerherve, Richard Kulpa, et al.. A musculoskeletal modelling approach of the assessment of the risk of hamstring injuries in professional soccer players: A pilot study. Computer Methods in Biomechanics and Biomedical Engineering, 2019, 5 (1), pp.55-58. 10.1080/24733938.2020.1786765 . hal-02429267

\section{HAL Id: hal-02429267 https://hal.science/hal-02429267}

Submitted on 6 Jan 2020

HAL is a multi-disciplinary open access archive for the deposit and dissemination of scientific research documents, whether they are published or not. The documents may come from teaching and research institutions in France or abroad, or from public or private research centers.
L'archive ouverte pluridisciplinaire HAL, est destinée au dépôt et à la diffusion de documents scientifiques de niveau recherche, publiés ou non, émanant des établissements d'enseignement et de recherche français ou étrangers, des laboratoires publics ou privés. 


\title{
A musculoskeletal modelling approach of the assessment of the risk of hamstring injuries in professional soccer players: A pilot study
}

\author{
M. Ménard ${ }^{\mathrm{a}, \mathrm{b} *}$, A. Sorel ${ }^{\mathrm{a}}$, R. Boumpoutou ${ }^{\mathrm{a}, \mathrm{c}}$, H.A. Kerhervéa ${ }^{\text {, R. Kulpa }}{ }^{\mathrm{a}}$ and B. Bideau ${ }^{\mathrm{a}}$ \\ ${ }^{a}$ Univ Rennes, M2S - EA 7470, F-35000 Rennes; ' Institut d'Ostéopathie de Rennes, Rue Blaise Pascal, Bruz, France, \\ France; ${ }^{c}$ Stade Rennais FC - La Piverdière - Chemin de la Taupinais 35039, Rennes, France
}

Keywords: overuse injury; muscle strain; opensim; simulation; injury prevention

\section{Introduction}

Hamstring injuries are the most common non-contact injuries in football and negatively affect team performance and club finances (Buckthorpe et al. 2019). Despite an abundant literature, the evaluation of the risk of hamstring injuries remains complex as it lacks evidence-based recommendations and reliable fieldtesting. The aetiology is commonly acknowledged as "multifactorial" and numerous potential risk factors have been proposed in the literature including muscle weakness, decreased flexibility, posture, fatigue, etc. (Gabbe et al. 2006). It most commonly occurs in the Biceps Femoris long head (BFlh) and a previous history (in the last 12 months) is considered the main predictor of subsequent hamstring injury. Previous experimental research showed that kinematic analysis provides a global external insight but fails to apprehend musculoskeletal solicitations (Thelen et al. 2006). On the contrary, analysis of musculoskeletal parameters (e.g. muscle length or strain rate) appears more relevant but direct measurement on the field is impossible, and only quantifiable through musculoskeletal modelling (Delp et al. 2007). The aim of this study was to investigate the risk of hamstring injury using a musculoskeletal approach during a functional test designed for this purpose.

\section{Methods}

\subsection{Participants}

Twelve professional elite footballers (age: $24 \pm 4$ years, height: $183 \pm 12 \mathrm{~cm}$, weight: $85 \pm 12 \mathrm{~kg}$ ) volunteered to participate in the study. Players were distributed in two groups, whether they sustained a hamstring history injury in the previous year ("Injured"; $\mathrm{N}=5$ ) or with no history of hamstring injury ("Control"; $\mathrm{N}=7$ ).

Players were informed of study protocol prior to inclusion and that they could withdraw at any time without penalty. All components of the study were designed according to the principles of the Declaration of Helsinki and were approved by the Sports Science and Medical Department of the Stade Rennais Football Club (\#2018-005-SRFC), and all trials were supervised by a medical doctor.

\subsection{Protocol}

After a 15-min standardised warm-up, participants performed a reactive agility task consisting in reaching one of four ground targets from a jumping start based on a visual cue displayed on a large screen whilst players where jumping. Players were instructed to reach a given target using the heel of their ipsilateral foot with leg stretched out, toes raised, and ipsilateral hand as close as possible to the target. Targets were located on the ground in front of them, oriented at $15^{\circ}$ and $50^{\circ}$ on right and left sides, and trial order was randomised. The test was considered complete when four successful trials on each target were recorded (Figure 1).

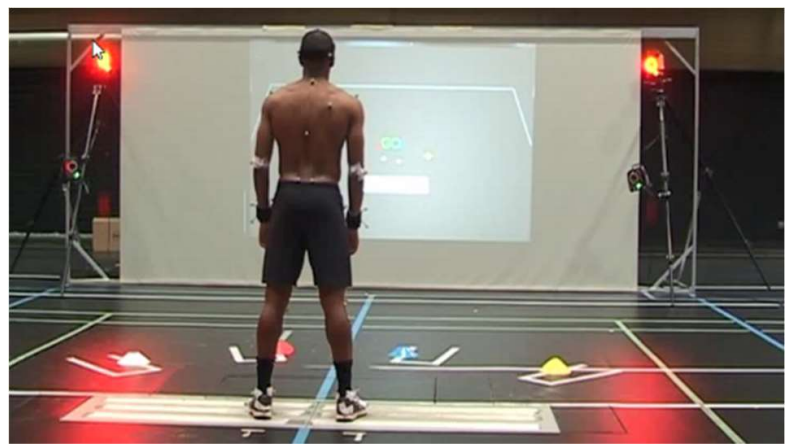

Figure 1: Overview of the experimental setup

\subsection{Musculoskeletal modelling}

Three-dimensional kinematics were obtained from a 24camera motion analysis system (Vicon, Oxford, UK). Marker data served as input of a full musculoskeletal model, developed by Lai et al. (2017) to estimate lumbar and lower limb joint angles from the recommended OpenSim calculation steps (Delp et al. 2007). The model was scaled to match participant's anthropometry and joint angles were calculated through a global optimisationbased inverse kinematics procedure. Maximal BFlh muscle length was estimated and normalised relative to resting length.

Dependent variables used for group comparisons were normalised maximal BFlh length, BFlh stretch time from resting length to maximum length, and stretch rate calculated as the ratio between the first two dependent variables. Lower limb joint angles were estimated and compared between groups at the peak of BFlh.

\subsection{Statistical analysis}

Wilcoxon sum-rank test was conducted for all dependant variables. Significance level was set at $p<0.05$. 


\section{Results and discussion}

All participants performed the test. Four invalid trials were removed out of the 172 trials. We observed no significant difference between conditions $\left(15^{\circ}\right.$ and $50^{\circ}, \mathrm{p}$ $=0.65)$. Maximal BFlh length and time to stretch were significantly greater in the control group. Stretch rate was not significantly different across groups (Table 1).

\begin{tabular}{lccc}
\hline \multicolumn{1}{c}{ Variables } & Injured & Control & p \\
\hline $\begin{array}{l}\text { Normalised } \\
\text { maximal BFlh } \\
\text { length }\end{array}$ & $1.47 \pm 0.09$ & $1.54 \pm 0.04$ & $<0.01$ \\
\hline $\begin{array}{l}\text { BFlh stretch time } \\
\text { (s) }\end{array}$ & $0.39 \pm 0.10$ & $0.48 \pm 0.10$ & $<0.01$ \\
\hline $\begin{array}{l}\text { Stretch rate } \\
1.30 \pm 0.27\end{array}$ & $1.27 \pm 0.25$ & 0.45 \\
\hline $\begin{array}{l}\text { Table 1 Comparison of dependant variables between groups } \\
\text { (mean of all conditions and all participants). }\end{array}$
\end{tabular}

Kinematics associated with these muscle parameters revealed that participants of the control group had greater maximal hip flexion and pelvis anterior tilt, and a smaller knee flexion than injured players (Table 2).

\begin{tabular}{lccc}
\hline Joint angles & Injured & Control & p \\
\hline Pelvis anterior tilt & $-24.5 \pm 19.0$ & $-38.2 \pm 9.2$ & $<0.01$ \\
\hline Pelvis list & $3.0 \pm 4.2$ & $1.4 \pm 5.0$ & 0.63 \\
\hline Pelvis rotation & $2.8 \pm 6.5$ & $0.5 \pm 6.6$ & 0.65 \\
\hline Hip flexion & $91.1 \pm 20.5$ & $106.5 \pm 6.8$ & $<0.01$ \\
\hline Hip abduction & $-18.9 \pm 6.3$ & $-19.6 \pm 7.4$ & 0.81 \\
\hline $\begin{array}{l}\text { Hip internal } \\
\text { rotation }\end{array}$ & $13.7 \pm 10.8$ & $20.1 \pm 10.2$ & 0.07 \\
\hline Knee flexion & $-41.4 \pm 4.1$ & $-35.9 \pm 11.5$ & $<0.01$ \\
\hline
\end{tabular}

Table 2 Comparison of all joint angles estimated for each groups (mean of all conditions and all participants).

This approach permitted to uncover different muscle kinematics between previously injured and non-injured players, where the decrease of BFlh stretching capacity was linked to a different strategy or a difficulty to stretch posterior muscle chain during this field test. This means that limitations in range of motion were greater and met more rapidly in previously pathological injured players compared to control players.
Although parameters in the sagittal plane were relatively constant within groups, both groups were characterised by great inter-individual variability in other planes, especially in hip internal rotation.

\section{Conclusions}

The main finding of this study is that musculoskeletal modelling allowed to analyse musculoskeletal function in greater detail than with a kinematics assessment alone. A longitudinal investigation was in progress to confirm those findings. The association between a specific field test and a musculoskeletal approach developed in this pilot study gives new preliminary insights on the impact of a previous history of hamstring injury on lower limb kinematics and BFlh muscle length and can help assisting medical practitioners, coaches, sport physicians and physiotherapists to prevent hamstring injuries.

\section{Acknowledgements}

We gratefully acknowledge thank all athletes for their enthusiastic participation.

\section{References}

Buckthorpe, M., Wright, S., Bruce-Low, S., Nanni, G., Sturdy, T., Gross, A.S., Bowen, L., Styles, B., Villa, S.D., Davison, M., and Gimpel, M., 2019. Recommendations for hamstring injury prevention in elite football: translating research into practice. Br J Sports Med, 53 (7), 449-456.

Delp, Anderson, F.C., Arnold, A.S., Loan, P., Habib, A., John, C.T., Guendelman, E., and Thelen, D.G., 2007. OpenSim: Open-Source Software to Create and Analyze Dynamic Simulations of Movement. IEEE Transactions on Biomedical Engineering, 54 (11), 1940-1950.

Gabbe, B.J., Bennell, K.L., Finch, C.F., Wajswelner, H., and Orchard, J.W., 2006. Predictors of hamstring injury at the elite level of Australian football. Scandinavian Journal of Medicine \& Science in Sports, 16 (1), 7-13.

Lai, A.K.M., Arnold, A.S., and Wakeling, J.M., 2017. Why are Antagonist Muscles Co-activated in My Simulation? A Musculoskeletal Model for Analysing Human Locomotor Tasks. Annals of Biomedical Engineering, 45 (12), 2762-2774.

Thelen, D.G., Chumanov, E.S., Sherry, M.A., and Heiderscheit, B.C., 2006.

Neuromusculoskeletal models provide insights into the mechanisms and rehabilitation of hamstring strains. Exercise and sport sciences reviews, 34 (3), 135-141. 